\title{
BILATERAL OPTIC NEURITIS FOLLOWING CATARACT EXTRACTION*
}

\author{
BY \\ D. O'KEEFFE AND K. C. CHOUDHURY \\ Llwynypia Hospital, Glamorgan
}

OPTIC neuritis is a rare sequel of cataract extraction. Reese and Carroll (1958) described seventeen cases, of which nine were their own. Three of the patients, who had both eyes operated on, suffered the same complication in the second eye, but seven other patients had no complications in the second eye. They had found no other definite cases in the literature, and we have found only two further references to the condition. Townes (1960) mentioned optic neuritis as a complication of cataract extraction, and Mitchell, Anderson, and Anderson (1963), in a description of the post-operative complications of cataract extraction, reported that "one patient of the senior staff series developed retrobulbar neuritis post-operatively, or the optic nerve may have been injured with the retrobulbar needle".

\section{Case Report}

A man aged 50 came to the Eye Department of this hospital on January 21, 1959, complaining of loss of vision in the right eye.

Examination.-There was a mature cataract in the right eye and early lens opacity in the left. The visual acuity in the left eye was 6/9.

In July, 1961, the visual acuity was perception of light in the right eye, with accurate projection of light and counting fingers in the left. No other abnormality was noted. It was then decided to remove the cataract in the right eye.

Operation.-Intracapsular extraction was attempted on November 10, 1961, but the capsule ruptured, though most of it was successfully removed. Alpha-chymotrypsin was used. There were no other complications and the post-operative recovery was uneventful.

On January 5, 1962, glasses were ordered; the visual acuity was 6/18 partly for distance and N5, with correction $+4 \mathrm{D}$ sph.

There were some slight pigmentary changes which appeared to explain the failure to achieve normal vision.

Progress.-On February 28, 1962, the patient returned complaining of loss of sight in the right eye of rapid onset about a week previously.

The visual acuity in the right eye was less than 6/60. There was oedema of the optic nerve head, and the veins were congested. The peripheral visual field was full to $10 / 330 \mathrm{~mm}$. white test object. A skull $x$ ray appeared normal.

The left eye, apart from the cataract, appeared normal though it was impossible to see the fundus.

On March 5, the right visual field showed a lower nasal quadrantic hemianopic defect. On March 9, optic atrophy of the post-neuritic type was present; the disc was greyish-white in colour with filling of the physiological cup and somewhat contracted blood vessels. The visual acuity in the right eye was $3 / 60$ with irregular concentric contraction of the visual field. At this stage the case was considered to be one of optic neuritis coincident with a cataract extraction.

Operation.-Intracapsular extraction of the left lens was carried out on September 17, 1962, with no complications. Alpha-chymotrypsin was used. On November 6 glasses were ordered;

\footnotetext{
* Received for publication May 25, 1965.
} 
the visual acuity with correction was $6 / 9$ for distance and N.5. for near. The fundus and field were normal.

On November 23 and December 18, 1962, his condition remained the same.

Progress.-On February 22, 1963, the patient returned with loss of sight in the left eye. The visual acuity was $6 / 36$ for distance; there was oedema of the optic disc, and the veins were congested, but there were no haemorrhages or exudates. On February 28 the peripheral field showed irregular contraction with $5 / 330 \mathrm{~mm}$. white test object. The ocular tension was $22 \mathrm{~mm}$. $\mathrm{Hg}$.

The Wassermann reaction and Kahn test were negative. The E.S.R. was $6 \mathrm{~mm}$. hr and a skull $x$ ray was again normal.

Medrone $4 \mathrm{mg}$. twice daily for a week was followed by $2 \mathrm{mg}$. once daily, with vitamin $\mathrm{B}_{1} 50 \mathrm{mg}$. daily.

On April 16, 1963, the optic disc showed atrophic changes with filling of the physiological cup, with a greyish appearance and constricted vessels, but the visual acuity improved to 6/18. Medrone and vitamin $B_{1}$ were gradually withdrawn.

On September 11, 1963, the visual acuity was 6/9 partially for distance and N. 5 for near with correction, but the visual field still showed gross peripheral contraction.

Result.-No change has since been noted. During all this time the patient appeared to be in good general health, and did not complain of symptoms other than diminution of vision.

He was seen by two consultant neurologists who suggested that this might be a case of chiasmal compression due to arachnoiditis, but full neurologicalinvestigations, includingair encephalography, did not reveal any abnormality.

\section{Discussion}

In considering the cause of the condition, Reese and Carroll (1958) suggested that it might be due to acute hypotony, uveitis, optic atrophy due to injection, or macular oedema, but none of these conditions was present in either eye in our case.

Because our case and three of those described by Reese and Carroll were bilateral, we feel that the more likely explanation is that the cataract extraction precipitated a bilateral optic neuritis in a patient already predisposed to the condition. This led us to consider the causes of bilateral optic neuritis:

(a) Leber's hereditary optic atrophy-No family history of this condition was elicited in our case.

(b) Disseminated sclerosis-Neurological examination revealed no other abnormalities of the central nervous system.

$\left.\begin{array}{l}\text { (c) Devic's disease } \\ \text { (d) Temporal arteritis }\end{array}\right\}$ No other evidence of these conditions was found.

\section{Summary}

A case of bilateral optic neuritis following cataract extraction has been described. The cause is obscure but it appears that operative trauma was the precipitating factor. Systemic steroid therapy was followed by an improvement in the condition of the second eye and may therefore be indicated in the treatment of this condition.

We wish to thank Dr. C. Wells and Dr. J. Spillane, consultant neurologists, who kindly examined the patient.

\section{REFERENCES}

Mitchell, C. H., Anderson, B., Sr., and Anderson, B., Jr. (1963). S. med. J. (Bgham, Ala.), 56, 362. Reese, A. B., and Carroll, F. D. (1958). Amer. J. Ophthal., 45, 659.

TOWnes, C. D. (1960). Rev. bras. Oftal., 19, 129. 